\title{
LOCALIZED NAVIGATION SYSTEM FOR COLLEGE CAMPUS - A REVIEW PAPER
}

\author{
Danish Navale ${ }^{1}$, Rushikesh Gangurde ${ }^{2}$, Vaibhav Kale ${ }^{3}$, Prashant Nimbekar ${ }^{4}$, Janhavi Borse $^{5}$ \\ ${ }^{1,2,3,4}$ Student, Information Technology, SPPU, India; \\ ${ }^{5}$ Professor, Information Technology, SPPU, India \\ Email: \{'danishnavale26@gmail.com, rrushi.gangurde123@gmail.com, \\ 3vaibhavk.vk31@gmail.com, ${ }^{4}$ nimbekarprashant121@gmail.com, ${ }^{5}$ janhavi.borse@sitrc.org\}
}

\begin{abstract}
With the invent of GPS and associated technologies outdoor navigation is clearly possible with extraordinary accuracy now a day. but we're nevertheless in need of an green, dependable and cheaper technology for indoor navigation. current device use RFID, Bluetooth, magnetic discipline, and so on. which are available for indoor navigation and area tracking. It has very high upkeep cost, low navigation range and it's performance is susceptible to climate adjustments.
\end{abstract}

Key Words : Indoor navigation, localized navigation, RFID, Bluetooth, GPS

\section{Introduction}

Navigation is the technique of appropriately setting up the user's position after which displaying instructions to manual them thru viable paths to their desired vacation spot. The global Positioning machine is the maximum not unusual and the most utilized satellite navigation system. nearly each aircraft and ship inside the international employs some shape of GPS era. it is a era Framework providing place offerings for outdoor situations. whilst GPS does not deliver the precise region inside any big homes - Airports, Hospitals, workplace buildings, huge institute and so forth. Our system will provide the smooth localized navigation in huge institute through the use of the beacon sensor. Beacon body is one of the management frames in IEEE 802.eleven based WLANs. It contains all of the records about the network. Beacon frames are transmitted with the aid of the get entry to factor (AP) in an infrastructure fundamental service set (BSS). In IBSS network beacon era is sent among the stations. We proposes the shortest route shape the supply choice vicinity, we also uses the sound tag for clean conversation and for better expertise for give up user. in addition to for the correction of indoor positioning algorithm for indoor map framework they uses map data get entry to which provide a common get admission to to indoor map facts and this access can be used not only for positioning purposes but additionally for drawing maps, separated positioning modules which has a common interface e. g. for function updates of placed objects and for the configuration of sensors, map and object rendering it generate a map that is based on uncooked geographical information is referred to as rendering, seamless indoor and outside maps it's far the calculation of combined outside and indoor routes and the provision of correction facts for positioning, encapsulated and selectable framework Modules it encapsulate extraordinary rendering, positioning, routing and particular visualizations in a modules, cross platform assist many methods which are applied to attain an indoor map use sensor platform to a quire the geometry of an indoor space like octomap library with the aid of hornang that is implementation in robot working gadget (ROS) etc. with the realized framework it's far viable to cowl new project and with out re-growing repeating task.

\section{Literature Survey}

Thomas Graichen[1], proposed an approach, "A map framework using crowd-source data for indoor positioningand navigation" which presents a framework for indoor positioning and navigation cause by the use of open avenue map (OSM) for rendering commend outdoor and indoor maps and in addition they calculate the navigation routers.

kamphaeng kungeharoen[2], proposed an approach "Development of GPS-Based navigation for kasetsart university, kamphaes seen campus" Considering fact that college campus like kasetsart university campus is very large, consisting of many places and landmarks so tourist or the official receivers may face some problems such as confusion \& delay while visiting. To solve this type of problem they have guidelines on that campus for the travelling inside this campus so for this GPS-Based navigation is introduced with help of this tourist or other person get help or knowledge about that place the primary cause of that is to broaden a GPS-primarily based navigation device integrate with POI (factor of interest) database of area $\&$ locations in this campus. To do this, network application for phone was develop running on web browser. There system consist of some module like Map Configuration which uses Google Map APIs for connection to an application in order to display map, 
Destination Specification These process start with defining function which consist of java variable related to object current coordinates and destination coordinates, They uses PHP, AJAX, JAVA and JavaScript programming, Database Creation which is to get the coordinates of location they use to store that location information in MySQL database, Route Calculation by using principle of GPS technology they calculate the distance between the satellite and the GPS receiver.

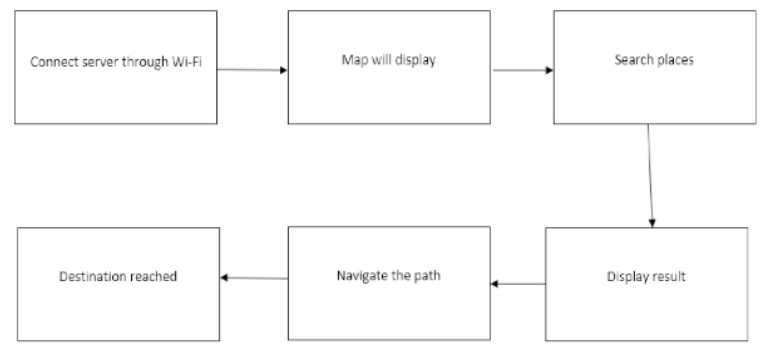

Fig. 1 : System Flow

Omran Hammadi [3], proposed an approach "Indoor localization \& Guidance using portable smartphones" these days, with the growing no. of homes it has turn out to be difficult for the each day traffic to don't forget indoors map of every of these places greater accurately. Indoor steering is becoming the good sized trouble with increasing no. of homes. This paper map guidance the site visitors inside buildings. It uses NFC (near field verbal exchange) generation and QR codes, which can be low as offer navigation with in the homes. In these gadget the person has to comply with following step

i The map of the constructing must be laid out and stored in a MapServer with a purpose to be to be had to the users. while the user, will use the gadget,they could examine the URL of the map from one of the NFC tag in the constructing.

ii The machine will ship the request of map from the server and down load it to the cellular.

iii The person can then view the downloaded map. similarly, he/she will perform extraordinary duties which includes locating the present day vicinity or navigating to a centered vacation spot.

iv To facilitate this, the consumer might for that reason want to experiment the closest NFC tag in the constructing.

Manoj Misra [4], proposed an approach "Smartphone Based Indoor tracking using magnetic and indoor maps" The growth of cellular computing \& person centric software to need for accurate and low fee indoor localization. Indoor localization uses brief variety sign like wireless, radio, ultrasound or Bluetooth sign.This paper display that the usage of magnetic maps initial sensors and indoor maps together improves the accuracy of localization. A real time telephone based utility tacking is advanced to test accuracy. The result of this approach indicates that the proposed approach gives the better accuracy than earlier method. these paper uses Orientation estimation the use of GDA set of rules which makes use of Gyroscopes and magnetometers, to estimate route of movement and Step Detection and also Particle filter out algorithm.

Binu plc[5], proposed an approach "An efficient indoor location tracking and navigation system using simple magnetic map matching" They expand an android based totally utility which allows green indoor navigation and tracks the exact region of human beings inside massive homes via the use of unique technologies like wifi, Bluetooth, RFID and so forth available for indoor navigation and location monitoring but the important trouble is implementation and renovation fee are very excessive and also it affect with the aid of the weather change in order that they innovates idea of magnetic subject identification generation which makes use of the evidently accuracy magnetic area inside the live performance buildings with simplified magnetic map matching algorithm by the use of clever cellphone with magnetic discipline sensor and all aerometer allows the application to provide the high-quality indoor navigation facilities to the end customers.

Brandon Gozick [6], proposed an approach "Magnetic Maps For Indoor Navigation ” This paper suggests that a magnetic map may be developed for each building by using the usage of a cellular telephone and its embedded sensors to emerge as an effective navigation tools. This magnetic field utilizing facts inside the buildings for localization and navigation purposes is an interesting factor to be studied. by means of using magnetic signatures we are able to locate some tough limitations like staircase, pillars and so on. additionally in college campus there are various locations in which the maps does no longer paintings nicely, so on this locations magnetic area have to increase it's power for higher result.

Sergio Lujan-Mora [7], proposed an approach "A Practical Example of a Collaborative Learning Experience For Engineering Students: How To Build Accessible Indoor Maps " This paper shows that their task increase an reachable indoor map which could assist blind human beings to attain their favored destination. This paper describe the grade by grade process followed to make an accessible indoor plan that complies with WCAG 2.zero accessibility guidelines. Examinator is an online device that checks code of internet site and plays a chain of exams related to conformance with the WCAG 2.zero tips. The WCAG additionally encompass check points to affirm testable errors. Checkpoints are assigned priority tiers are as follows:

priority 1. those are hints that a web developer must comply just so positive organizations of customers can get admission to the contents of a website. 
priority 2. those are hints that a web developer ought to comply simply so certain organizations of customers do no longer have many difficulties to get admission to the contents of a internet site.

precedence 3. those are hints that a web developer must comply just so certain organizations of users do not have extreme problems to get admission to the contents of a website. based on these priorities, WCAG established some different levels. That particularly improves performance of navigation device

Bartosz Brzozowski[8], as proposed an approach “ Magnetic Field Mapping as Support For UAV Indoor Navigation System "This paper presents ways of recording, visualizing and mapping neighborhood magnetic subject changes that can be used as a guide for indoor navigation structures. The oldest device using a magnetic discipline is the magnetic compass. It now acts as a alternative device inside the event of electronic system disasters and permits average manage of complex navigation processes. The idea of magnetometer is provide strong and accurate measurement. The end result of magnetic subject power information can be vital trace for indoor navigation device. The magnetometers are the primary components of avionic gadget on board unmanned aerial automobile. Their implementation permits measurements of magnetic area electricity in three axes to offer facts approximately the path and place in space. The received information lets in a proper repayment to growth the accuracy of the inertial measurement units. For this authors proposed the answer is to apply data obtained without delay from the sensors to decide the depth of the magnetic discipline in 3 axes at a given location and time. as soon as registered on the memory card, it is feasible to further generate a map of local trade in the magnetic field. Assuming that the exchange idem at fixed time c language, such map may be used to help the navigation device. The proposed vector plots will permit in destiny to decide the route for an unmanned aerial car, all through which an self reliant alternate of course of flight and altitude might be viable.

Hao Xue, Lin Ma [9], as proposed an approach “ A Fast Visual Map Building Method Using Video Stream for Visual-Based Indoor Localization " On this paper they advocate a quick visual map building technique for visual-based totally indoor localization, which will boom the accuracy of indoor localization, the dimensions of image database have to be as massive as feasible. The system of constructing a database that can be used for indoor localization is hard. hence, we advise a quick visible map constructing technique for visual-primarily based indoor localization, which takes completely use of comfort of video flow. as compared with present photobased totally indoor localization machine, the proposed device utilize video statistics is a great deal greater handy. The experimental results display that the proposed approach is applicable in the complicated indoor environment. visual map encompass geologic role \& state of affairs photo facts. using visual information offers us a higher way understanding and sensing the indoor surroundings. This technique makes use of SURF (speeded up sturdy functions) set of rules that could be a scale and rotation invariant descriptor to look matching pix and RANSAC (Random sample consensus) algorithm to exclude the a few blunders matching points.

Peng Zhuang[10], has proposed an approach " SMART: Simultaneous Indoor Localization and Map Construction Using Smartphones " On this paper, they advocate a unique device clever (Simultaneous Map Acquisition and Repeated tracking). via tracking a subject based on sensor inputs and radio alerts and detecting environmental fingerprints, smart achieves simultaneous indoor localization and surroundings map production using smartphones primarily based on radio signals from surrounding wireless access factors and their personal measured motion dynamics. smart is strong towards sensing mistakes and may mechanically adapt to environment changes. In region based totally programs, it's also vital to put together a database of geo-tagged statistics, which includes points of pursuits (POI) and maps. current global map services commonly do no longer provide certain floor plans and their POI lists are some distance from sufficient. similarly, it is difficult to right away reflect floor plan or POI modifications. for example, if a bookstore actions to a one-of-a-kind place at a strip mall, there is no green manner to update a national POI database except a user reports the mistake. in this paper, they are attempting to addresses the problems of indoor localization and map updating and offers a novel solution to solve each troubles concurrently. by tracking a topic based totally on sensor inputs and radio alerts and detecting surroundings fingerprints, clever achieves simultaneous in-door localization and surroundings map creation the use of smartphones primarily based on radio signals from surrounding wireless get entry to points and their personal measured movement dynamics. The clever may be very new gadget for in-door localization and surroundings logical map construction. The logical map constructed can be similarly exceptional tuned to in shape the wishes of diverse programs. So, this machine is very useful for big campus universities additionally some big complicated to present extra element view of that unique place.

Table 1

Summary of the Techniques

\begin{tabular}{|c|l|l|}
\hline $\begin{array}{c}\text { Paper } \\
\text { No. }\end{array}$ & \multicolumn{1}{|c|}{ Pros } & \multicolumn{1}{c|}{ Cons } \\
\hline 1$)$ & $\begin{array}{l}\text { 1.It uses separate } \\
\text { Positioning modules } \\
\text { for accurate result. } \\
\text { 2.It covers new task } \\
\text { without re-developing } \\
\text { repeating task. }\end{array}$ & $\begin{array}{l}\text { 1. It uses old style of } \\
\text { track and trace using } \\
\text { robot positioning } \\
\text { system. }\end{array}$ \\
\hline
\end{tabular}




\begin{tabular}{|c|c|c|}
\hline 2) & $\begin{array}{l}\text { It uses POI database of } \\
\text { location and place in } \\
\text { the campus }\end{array}$ & $\begin{array}{l}\text { People get confuse or } \\
\text { get delay to visit } \\
\text { the place in the lager } \\
\text { campus }\end{array}$ \\
\hline 3) & $\begin{array}{l}\text { It uses QR code which } \\
\text { is higher than barcodes } \\
\text { which has high } \\
\text { capability of encoding } \\
\text { records. It additionally } \\
\text { uses NFC tags to } \\
\text { determine the modern- } \\
\text { day function inner a } \\
\text { building via touching } \\
\text { cell tool to NFC tags }\end{array}$ & $\begin{array}{l}\text { In this they uses NFC } \\
\text { technology which is } \\
\text { useful but this NFC } \\
\text { hardware in not present } \\
\text { in every single mobile }\end{array}$ \\
\hline 4) & $\begin{array}{l}\text { It makes use of the } \\
\text { magnetic discipline } \\
\text { maps together with } \\
\text { some inertial sensor } \\
\text { which is less expensive } \\
\text { than the wifi, radio } \\
\text { ultrasound. }\end{array}$ & $\begin{array}{l}\text { In this they uses } \\
\text { magnetic field which } \\
\text { increase the cost of the } \\
\text { system. }\end{array}$ \\
\hline 5) & $\begin{array}{l}\text { With uses of magnetic } \\
\text { subject technology } \\
\text { which uses naturally } \\
\text { happening magnetic } \\
\text { field inside building } \\
\text { which is good for the } \\
\text { gadget }\end{array}$ & $\begin{array}{l}\text { The method would fail if } \\
\text { you have not enough } \\
\text { anomalies or if the } \\
\text { environment is changes } \\
\text { Magnetic field add } \\
\text { noise which will disrupt } \\
\text { the accuracy of location. }\end{array}$ \\
\hline 6) & $\begin{array}{l}\text { The no. of landmarks } \\
\text { and their keeping apart } \\
\text { distance Can then be } \\
\text { applied in the course of } \\
\text { the building to offer } \\
\text { clean evaluation whilst } \\
\text { integrating the } \\
\text { constructing with } \\
\text { indoor navigation. } \\
\text { those are two one of a } \\
\text { kind varieties of } \\
\text { magnetic field } \\
\text { particularly static and } \\
\text { dynamic. }\end{array}$ & $\begin{array}{l}\text { Due to using the } \\
\text { magnetic field cost of } \\
\text { the system increase and } \\
\text { the accuracy is up to } \\
70 \% \text {. }\end{array}$ \\
\hline 7) & $\begin{array}{l}\text { Making lifestyles less } \\
\text { complicated and } \\
\text { permitting humans to } \\
\text { each day tasks rapidly } \\
\text { together with to be } \\
\text { located in unknown } \\
\text { building. it's miles tool } \\
\text { independence and } \\
\text { available navigation. }\end{array}$ & $\begin{array}{l}\text { The learnt that the } \\
\text { barrier for navigation } \\
\text { constructing that face } \\
\text { human beings with in } \\
\text { disabilities also affect to } \\
\text { human beings with out } \\
\text { disabilities. }\end{array}$ \\
\hline
\end{tabular}

\begin{tabular}{|l|l|l|}
\hline 8$)$ & $\begin{array}{l}\text { They uses designed } \\
\text { and improvement of a } \\
\text { measuring module for } \\
\text { indoor navigation they } \\
\text { makes use of 3 low } \\
\text { price money properly } \\
\text { object 5883L,3 axis } \\
\text { magnetometer, a } \\
\text { reminiscence card } \\
\text { reader an arduino } \\
\text { microprocessor gadget } \\
\text { and a computer which } \\
\text { could method offline. } \\
\text { magnetometer gives } \\
\text { stable and comparable } \\
\text { measurement but } \\
\text { supply reference value } \\
\text { of a magnetic field } \\
\text { chosen area }\end{array}$ \\
\hline 9) & $\begin{array}{l}\text { It uses visual maps for } \\
\text { indoor localization } \\
\text { which use in inside } \\
\text { building where GPS } \\
\text { signal are often not } \\
\text { available. } \\
\text { so it will be helpful to } \\
\text { user to navigate. }\end{array}$ & $\begin{array}{l}\text { It has very high cost as } \\
\text { compare to traditional } \\
\text { system. }\end{array}$ \\
\hline $\begin{array}{l}\text { They makes use of the } \\
\text { clever (Simultaneous } \\
\text { for addressing the } \\
\text { problems, which could } \\
\text { be very useful for his } \\
\text { or her system. }\end{array}$ & $\begin{array}{l}\text { But by using the } \\
\text { SMART it increase the } \\
\text { cost of the system and it } \\
\text { needs the smartphones } \\
\text { to access. }\end{array}$ \\
\hline
\end{tabular}

\section{Conclusion}

The extensive survey is carried out and is summarized in the Table 1. The approach [1] gives the indoor positioning by using OSM and using Robot operating system it gives the correct positioning inside the building. It is more cost effective as compared to other approaches. The other approach uses the magnetic field inside the building for indoor positioning which increase the cost of the system and also degrades the performance when the climate changes.

\section{Acknowledgment}

This paintings is supported via branch of information technology, Sandip Institute of technology and studies Centre, Sandip foundation Nashik. I take this opportunity to explicit gratitude to all department faculty individuals for his or her help \& help. I additionally thank my parents for the unceasing encouragement and help. 


\section{References}

[1] Thomas Graichen, Erik Gruschka, Ulrich Heinkel, " A Map Framework Using Crowd-Sourced Data For Indoor Positioning And Navigation ", IEEE 2017

[2] Siriwan Chompukaew, Kwanchai Kungcharoen, Wichian Premchaiswadi, "Development of GPSBaased Navigator for Kasetsart University, Kamphaeng Saen Campus "2016 IEEE

3] Omran Al Hammadi, Ahmed Al Hebsi, M Jamal, Jason W P Ng, " Indoor Localization And Guidance Using Portable Smartphones ", IEEE 2012

[4] Ramakanth Putta, Manoj Misra, Divye Kapoor, “ Smartphone Based Indoor Tracking Using Magnetic And Indoor Maps", IEEE 2015 Tenth International Conference on Intelligent Sensors, Sensor Networks and Information Processing (ISSNIP)

[5] Binu P K, Akhil Krishnan R, Pranavkumar A, “An Efficient Indoor Location Tracking And Navigation System Magnetic Map Matching " IEEE 2016
[6] Brandon Gozick, Kalian Pathapati, Ram Dantu, Tomyo Maeshiro, “ Magnetic Maps For Indoor Navigation ", IEEE 2011

[7] Sandra Sanchez-Gordon, Sergio Lujan-Mora, “ A Practical Example Of A Collaborative Learning Experience For Engineering Students : How To Build Accessible Indoor Maps ”, IEEE 2015

[8] Bartosz Brzozowski, Krzysztof Kazmierczak, “ Magnetic Field Mapping as a Support for UAV Indoor Navigation Sysytem ”, IEEE 2017

[9] Hao Xue, Lin Ma, Xuezhi Tan, “A Fast Visual Map Building Method Using Video Stream for VisualBased Indoor Localization”, IEEE 2016

[10] Peng Zhuang, Dan Wang, Yi Shang, “ SMART : Simultaneous Indoor Localization and Map Construction Using Smartphones ”, IEEE 2010 